\title{
Coupling immuno-magnetic capture with LC-MS/MS(MRM) as a sensitive, reliable, and specific assay for SARS-CoV-2 identification from clinical samples
}

\author{
Ofir Schuster ${ }^{1}$ - Yafit Atiya-Nasagi ${ }^{1}$ - Osnat Rosen ${ }^{2} \cdot$ Anat Zvi $^{3} \cdot$ Itai Glinert $^{1} \cdot$ Amir Ben Shmuel $^{1}$. Shay Weiss ${ }^{1}$. \\ Orly Laskar $^{1} \cdot$ Liron Feldberg $^{4}$ (i)
}

Received: 30 September 2021 / Revised: 21 November 2021 / Accepted: 3 December 2021 / Published online: 4 January 2022

(c) Springer-Verlag GmbH Germany, part of Springer Nature 2021

\begin{abstract}
Recently, numerous diagnostic approaches from different disciplines have been developed for SARS-CoV-2 diagnosis to monitor and control the COVID-19 pandemic. These include MS-based assays, which provide analytical information on viral proteins. However, their sensitivity is limited, estimated to be $5 \times 10^{4} \mathrm{PFU} / \mathrm{ml}$ in clinical samples. Here, we present a reliable, specific, and rapid method for the identification of SARS-CoV-2 from nasopharyngeal (NP) specimens, which combines virus capture followed by LC-MS/MS(MRM) analysis of unique peptide markers. The capture of SARS-CoV-2 from the challenging matrix, prior to its tryptic digestion, was accomplished by magnetic beads coated with polyclonal IgG- $\alpha$-SARS-CoV-2 antibodies, enabling sample concentration while significantly reducing background noise interrupting with LC-MS analysis. A sensitive and specific LC-MS/MS(MRM) analysis method was developed for the identification of selected tryptic peptide markers. The combined assay, which resulted in S/N ratio enhancement, achieved an improved sensitivity of more than 10-fold compared with previously described MS methods. The assay was validated in 29 naive NP specimens, 19 samples were spiked with SARS-CoV-2 and 10 were used as negative controls. Finally, the assay was successfully applied to clinical NP samples $(n=26)$ pre-determined as either positive or negative by RT-qPCR. This work describes for the first time a combined approach for immuno-magnetic viral isolation coupled with MS analysis. This method is highly reliable, specific, and sensitive; thus, it may potentially serve as a complementary assay to RT-qPCR, the gold standard test. This methodology can be applied to other viruses as well.
\end{abstract}

Keywords SARS-CoV-2 $\cdot$ Immunomagnetic capture $\cdot$ LC-MS/MS(MRM) $\cdot$ Clinical samples $\cdot$ Signal to noise ratio

Ofir Schuster and Liron Feldberg contributed equally to this work.

Ofir Schuster
ofirsc@iibr.gov.il
Liron Feldberg
lironf@iibr.gov.il

1 Department of Infectious Diseases, Israel Institute for Biological Research (IIBR), Ness Ziona, Israel

2 Department of Biotechnology, IIBR, Ness Ziona, Israel

3 Department of Biochemistry and Molecular Genetics, IIBR, Ness Ziona, Israel

4 Department of Analytical Chemistry, IIBR, Ness Ziona, Israel

\section{Introduction}

Severe acute respiratory syndrome coronavirus 2 (SARSCoV-2), responsible for the COVID-19 pandemic, emerged at Wuhan, China [1], and rapidly spread globally causing an enormous public health crisis. The SARS-CoV-2 genome encodes twenty-two functional and four structural proteins [2-4]. The four structural components of the virus are as follows: (1) Spike glycoprotein (S) that binds to angiotensin-converting enzyme 2 (ACE2) receptor and enables cell penetration; (2) Nucleoprotein $(\mathrm{N})$ that stabilizes the viral RNA [5]; (3) Envelope protein (E) which has both structural and functional aspects, and (4) Membrane protein (M) that forms the virus' outer layer. The fact that $\mathrm{N}$ and $\mathrm{S}$ are the most abundant proteins in the virus [4] makes them preferred targets for antigen-SARS-CoV-2 identification [6]. 
Currently (September 2021), the death toll for this worldwide pandemic has exceeded $4 \mathrm{M}$ people with over $200 \mathrm{M}$ verified cases (https://www.worldometers.info/coronavirus/). Due to high human-to-human transmission rate [7], quarantine and physical distancing are the main tool for disease control and prevention [8], in concurrence with an ongoing global vaccination campaign. Therefore, rapid and reliable diagnosis of SARS-CoV-2 infected individuals is of high importance. According to the World Health Organization (WHO), the gold standard assay for SARS-CoV-2 diagnosis is quantitative reverse transcription polymerase chain reaction (qRT-PCR), a nucleotide-based testing for viral RNA in nasopharyngeal (NP) swabs, collected from the upper respiratory tracts of suspected individuals [3, 9]. This assay is highly sensitive (limit of detection is estimated as $1 \mathrm{PFU} /$ $\mathrm{ml}[10])$ and enables high-throughput analysis. However, due to its extreme sensitivity, positive RT-qPCR results may identify residual viral RNA, falsely identifying samples in which no viral culture is achieved [11]. Thus, insufficient correlation to virus viability and infectivity is a limitation of this technique [12]. Furthermore, nucleic acid tests are susceptible to inhibition by clinical matrices, leading to possible false negative results [13-16]. Alternatively, antigen-based assays have been developed, yet their sensitivity is too low, estimated to start at approximately $5 \times 10^{4} \mathrm{PFU} / \mathrm{ml}[6,17]$.

Mass spectrometry (MS)-based techniques are simple, rapid, accurate, and reliable, therefore widely used for diagnosis of microorganisms in clinical laboratories [18]. Although these technologies mainly focused on bacterial identification, they have also been applied for the identification of viruses directly or by detecting the molecular phenomena associated with pathogenesis [19]. In the first SARS outbreak (2003), MS techniques were successfully applied for the detection of its $S$ and $\mathrm{N}$ protein characterizations [20-22]. During the current SARS-CoV-2 pandemic, many reports demonstrated the ability to identify viral proteins based on MS methods as a potential complementary assay for COVID-19 diagnosis and research. These studies were found to be applicable for viral identification from cell cultures as well as from complex biological clinical samples [23-26]. Gouveia et al. listed candidate peptide markers derived from the virus $\mathrm{N}, \mathrm{S}$, or $\mathrm{M}$ proteins, for the specific identification of the virus by targeted LC-MS/MS technique [27], and in further study they developed a shortened assay applicable for high-throughput LC-MS analysis, based on two best markers derived from $\mathrm{N}$ protein [28]. Recently, a study from our lab presented a rapid and reliable assay for SARS-CoV-2 identification based on specific markers derived from $\mathrm{N}$ and $\mathrm{S}$ SARS-CoV-2 proteins using high-resolution mass spectrometry. This assay enabled direct identification of $5 \times 10^{4} \mathrm{PFU} / \mathrm{ml}$ [29] SARS-CoV-2 in spiked buffer and an order of magnitude higher in NP specimens. These promising emerging MS-based methods are specific and rapid and may be beneficial as a research tool, or to supplement the diagnostic testing of COVID-19. These methods are characterized by direct processing of clinical samples, without prior virus separation. While the advantage of this methodology is its speed and simplicity, it suffers from low sensitivity originating from the complexity of the specimen matrix to LC-MS analysis [27, 30]. To enable effective COVID-19 diagnosis based on MS analysis, the assay's sensitivity needs to be improved.

To improve the performances of MS-based assays, instrumental and sample preparation strategies should be implemented. MS analysis based on multiple reaction monitoring (MRM) target mode is highly sensitive and specific; therefore, it can selectively identify and quantify compounds within complex clinical matrices. In addition, virus separation from viral transport medium (VTM) and the clinical matrix may reduce the interfering background while concentrating the target viruses' proteins, increasing assay sensitivity. Separation based on immunomagnetic beads coated with polyclonal antibodies (Abs) allows efficient and specific capture of viruses as previously demonstrated with koi herpesvirus [31], enterovirus 71 [32], or hepatitis A virus [33]. A preliminary assay, in which SARS-CoV-2 capture is conducted by immobilization of its ACE receptor to modified ferrite magnetic beads, was previously suggested [34]. Another study presented a high accuracy of SARS-CoV-2 identification using immunocapture of N-protein combined with targeted MS and a machine learning-based model [35]. However, to date, the approach of SARS-CoV-2 capture and enrichment using immunomagnetic-beads separation has not been published.

The following study focused on immunomagnetic SARS-CoV-2-specific enrichment from challenging matrices, prior to its tryptic digestion, combined with the development of sensitive LC-MS/MS(MRM) analysis. The capture process was found to be efficient in separating virus particles from challenging clinical matrix, enabling both virus concentration and interference reduction.

COVID-19 diagnosis is based on our previous reported unique peptide markers panel derived from tryptic SARSCoV-2 S and N proteins [29]. The assay's development includes method performance evaluation using purified viral proteins, cultured virus, and negative NP clinical samples spiked with the virus. The applicability in qRT-PCR pre-determined positive or negative NP swabs collected from human patients is assessed as well. The proposed novel approach was found to increase the sensitivity to $5 \times 10^{3} \mathrm{PFU} / \mathrm{ml}$, an order of magnitude better than previously reported MS methods. The IMS technique presented herein may be implemented in other viral identification assays, for the purpose of improving sensitivity and specificity. 


\section{Materials and methods}

\section{Reagents}

All solvents and chemicals used in LC-MS/MS analysis were of LC-MS grade. Acetonitrile (Cat. Number 120410100), water (Cat. Number 232141B1), and formic acid (99\% purity, Cat Number 691413) were purchased from Bio-Lab. Ammonium bicarbonate $\left(\mathrm{NH}_{4} \mathrm{HCO}_{3}\right.$, Cat Number A6141-500G) and octyl- $\beta$-D-glucopyranoside (OG, Cat Number O8001-1G) were acquired from Sigma-Aldrich. Peptides [SFIEDLLFNK (S-11), FLPFQQFGR (S-16), FQTLLALHR (S-18), HTPINLVR (S-26), AYNVTQAFGR (N-5), and GFYAEGSR (N-8)] were synthesized by Merck (Sigma-Aldrich, Israel) with a purity $>95 \%$. These peptides were used for the development of the MRM method. Phosphate-buffered saline (PBS, pH 7.4, Cat. Number 02-0231A), sequencing-grade modified trypsin (Cat. Number V5111), and bovine serum albumin (BSA, Cat. Number 03-010-1B) were purchased from Biological Industries.

\section{Cell lines and viruses}

African green monkey kidney clone E6 cells (Vero E6, ATCC $\left(\right.$ CRL-1586 ${ }^{\mathrm{TM}}$ ) were grown in Dulbecco's modified Eagle's medium (DMEM) containing 10\% fetal bovine serum (FBS), MEM non-essential amino acids (NEAA), $2 \mathrm{mM}$ L-glutamine, 100 units $/ \mathrm{ml}$ penicillin, $0.1 \mathrm{mg} / \mathrm{ml}$ streptomycin, and 12.5 units $/ \mathrm{ml}$ nystatin $(\mathrm{P} / \mathrm{S} / \mathrm{N})($ Biological Industries, Israel). Cells were cultured at $37{ }^{\circ} \mathrm{C}$, in a $5 \%$ $\mathrm{CO}_{2}$ in $95 \%$ air atmosphere.

SARS-CoV-2 (GISAID accession EPI_ISL_406862) stocks were propagated (4 passages) and tittered on Vero E6 cells. All virus handling and work were conducted in a BSL3 facility in accordance with the biosafety guidelines of the Israel Institute for Biological Research (IIBR). Viral titers were determined by plaque assay, as previously described [29].

\section{Antibodies (Abs)}

Specific anti-Spike polyclonal Abs (termed "R15") were prepared by immunizing a female New Zealand white rabbit with $200 \mu \mathrm{g}$ of purified Spike protein (prepared as described [36]), in complete Freund's adjuvant by subcutaneous injection. The vaccination regime included two additional boost doses (150 $\mu \mathrm{g}$ each), given in 4-week intervals in incomplete Freund's adjuvant. Anti-SARSCoV-2 polyclonal Abs (termed "R606") were prepared as described [37]. Rabbits were inoculated five times intravenously with $10^{6} \mathrm{PFU}$ of live SARS-CoV-2 at days $0,7,10,14$, and 17 PI. Serum was collected 10 or 14 days after the final dose (for $\alpha$-Spike or $\alpha$-SARS-CoV-2, respectively), and the $\operatorname{IgG}$ fraction was purified as previously described [36, 37]. Biotinylation of the purified IgG fraction was carried out as previously described [6].

\section{SARS-CoV-2 enrichment}

Commercial magnetic beads, in a diameter of 1 or $2.8 \mu \mathrm{m}$ coated with streptavidin (Dynabeads MyOne Streptavidin T1 or M280, Invitrogen, Norway), were blocked with 5\% bovine serum albumin (BSA) solution, and washed twice with PBS, followed by resuspension at the original beads' volume. The beads were bound to biotinylated polyclonal Abs by rotating for $10 \mathrm{~min}$ in an Eppendorf tube at room temperature, followed by washing twice with PBS to remove excess unbound Abs.

Two capture protocols were examined, sequential or "all in one." The sequential approach included binding the biotinylated Abs to the streptavidin-coated beads, washing the residual unbound Abs, and then capturing the viruses from the sample followed by a washing series. In the "all in one" approach, a mixture of beads, unbound Abs, and the sample containing viruses were mixed together.

The final capture of virus from clinical NP samples in commercial transfer buffer was performed in test tubes pre-blocked with $0.5 \%$ BSA, to eliminate virus adsorbance. Twenty microliters of beads bound to Abs was added to each test tube, containing 1-ml sample. The tubes were rotated at $37{ }^{\circ} \mathrm{C}$ for 30 min followed by a washing series using decreasing buffer volumes $(800,500,200 \mu \mathrm{l})$ with gentle vortexing between each step, and included tube replacement prior to the final resuspension with $100 \mu \mathrm{l}$ buffer, corresponding to a tenfold sample concentration.

\section{Tryptic digestion}

Tryptic digestion was conducted as previously described $[29,38]$. Briefly, a total volume of $100 \mu \mathrm{l}$ of the samples (SARS-CoV-2 purified N or S proteins, buffer spiked viruses or clinical NP swabs) was heated for denaturation ( $95{ }^{\circ} \mathrm{C}, 10 \mathrm{~min}$.). After 2 -min cooling, $2 \mu \mathrm{l}$ of sequencing-grade modified trypsin $(0.5 \mu \mathrm{g} / \mu \mathrm{l})$ and $2 \mu \mathrm{l}$ of $10 \%$ octyl- $\beta$-D-glucopyranoside were added (final concentration $1 \mu \mathrm{g} / 100 \mu \mathrm{l}$ and $1 \%$, respectively) to the sample tubes, followed by 120 -min incubation at $50{ }^{\circ} \mathrm{C}$ with continuous rotation $(600 \mathrm{rpm})$. The tryptic digestion was stopped by adding $10 \mu \mathrm{l}$ of $10 \%$ formic acid (final concentration $1 \%$ ), followed by 2 -min centrifugation $(14,000 \mathrm{rpm})$. The resulting supernatants were transferred to LC-MS analysis vials. 


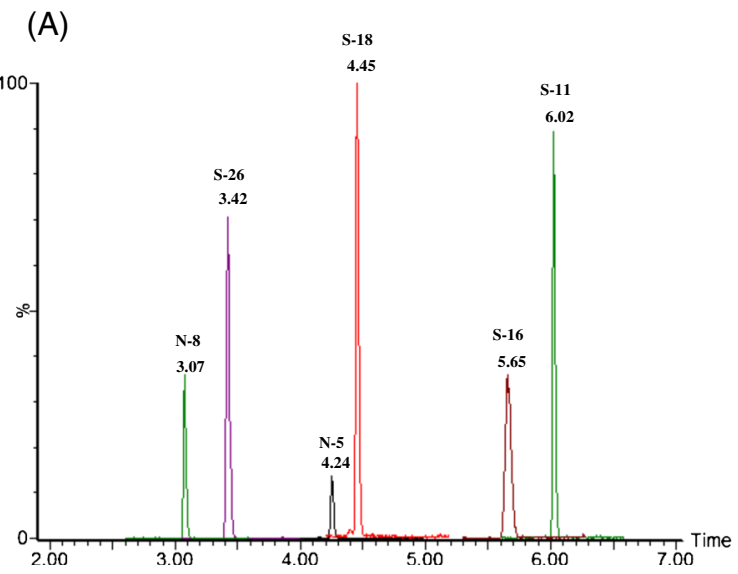

Fig. 1 (A) Overlay LC-MS/MS chromatograms (TICs of MRMs) of six synthetic peptides (1 ppb). (B) Peptides and their MRM transitions extending from multiple charge molecular ions to their fragments. Y, Ions that result from the cleavage of the $\mathrm{C}-\mathrm{N}$ bonds (amide bonds) of a peptide backbone with the $\mathrm{C}$-terminal fragments retaining the charge. $\mathrm{b}$, Ions that result from the cleavage of the $\mathrm{C}-\mathrm{N}$ (amide bond) bonds of a peptide backbone with the $\mathrm{N}$-terminal fragments

\section{Clinical samples and RT-qPCR}

NP swabs from suspected COVID-19 patients were transported to our lab in a viral transport medium (Copan Diagnostics, Inc.). Samples were kept at $4{ }^{\circ} \mathrm{C}$ until use, and randomly selected for this study. Clinical sample processing was done by vortexing the swabs vigorously for $30 \mathrm{~s}$ to release the virus into solution. First, $1 \mathrm{ml}$ of each specimen was incubated for an hour with magnetic beads conjugated to specific antibodies directed to SARS-CoV-2 (R606). Then, the bound viruses were vortexed and introduced into $0.1 \mathrm{ml}$ of ammonium bicarbonate buffer, inactivated at $95{ }^{\circ} \mathrm{C}$ for $10 \mathrm{~min}$, and subjected to tryptic digestion for $2 \mathrm{~h}$ at $50{ }^{\circ} \mathrm{C}$. The reaction was ended by adding formic acid at a final concentration of $1 \%$ and followed by LC-MS/MS(MRM) analysis. The overall process takes about $4 \mathrm{~h}$. The RT-qPCR assay was performed according to $\mathrm{WHO}$ instructions, as previously described [10], using the SensiFAST Probe Lo-ROX One-Step kit (Bioline). Primers and probe for SARS-CoV-2 E gene were according to the Berlin protocol [39].

\section{LC/QqQ/MS-MS(MRM) analysis}

The LC-MS system consisted of Acquity UPLC-I class (SMFTN) coupled with a Xevo TQ-S Triple Quadropole mass spectrometer (Waters Corporation, Milford, MA), operated with a positive ESI (electrospray ionization) source in MRM (multiple reaction monitoring) mode. Several running conditions (columns, temperatures, mobile phases, $\mathrm{pH}$ 's, and gradient compositions) were tested for optimal sensitivity and chromatography speed of the six marker peptides using
(B)

\begin{tabular}{|c|c|c|}
\hline Peptides & $\begin{array}{c}\text { Parent ion } \mathbf{m} / \mathbf{z} \\
\text { (Multiple charged) }\end{array}$ & Fragments $\mathbf{m} / \mathbf{z}$ (types) \\
\hline \multirow[t]{2}{*}{ FQTLLALHR (S-18) } & $549.8(2+)$ & $\begin{array}{l}86.1(\mathrm{imm} \mathrm{Ile})^{+1}, 110.1(\mathrm{imm} \mathrm{His})^{+1}, 120.1(\mathrm{imm} \text { Phe })^{+1} \\
175.1\left(\mathrm{Y}_{1}\right)^{+1}, 276.1\left(\mathrm{~b}_{2}\right)^{+1}, 496.2\left(\mathrm{Y}_{4}\right)^{+1}, 609.4\left(\mathrm{Y}_{5}\right)^{+1}, 823.5\left(\mathrm{Y}_{7}\right)^{+1}\end{array}$ \\
\hline & $366.9(3+)$ & 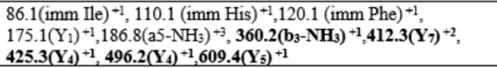 \\
\hline GFYAEGSR (N-8) & $443.7(2+)$ & $\begin{array}{l}\text { 120.1 (imm Phe })^{+1}, 136.1(\mathrm{imm} . \mathrm{Tyr})^{+1}, 176.6\left(\mathbf{6 3}-\mathrm{NH}_{3}\right)^{+2} \\
319.2\left(\mathrm{Y}_{3}\right)^{+1}, 341.7\left(\mathrm{Y}_{6}\right)^{+2}, 448.2\left(\mathrm{Y}_{4}\right)^{+1}, 519.3\left(\mathrm{Y}_{6}\right)^{+1}, 682.3\left(\mathrm{Y}_{6}\right)^{+1}\end{array}$ \\
\hline HTPINLVR (S-26) & $475.3(2+)$ & $\begin{array}{l}70.1(\mathrm{imm} \text { Pro })^{+1}, \mathbf{1 1 0 . 1}(\mathrm{imm} \mathrm{His})^{+1}, \mathbf{2 3 9} .1\left(\mathbf{b}_{2}\right)^{+1}, \mathbf{4 6 6 . 3}\left(\mathrm{C}_{4} \text { or } \mathrm{Z}_{4-}\right. \\
\left.\mathbf{H}_{2} \mathbf{O}\right)^{+1}, 501.3\left(\mathrm{Y}_{4}\right)^{+1} 711.5\left(\mathrm{Y}_{6}\right)^{+1}, 812.5\left(\mathrm{Y}_{7}\right)^{+1}, 821.5\left(\mathrm{X}_{7}-\mathrm{NH}_{3}\right)^{+1}\end{array}$ \\
\hline IYNVTQAFGR (N-5) & $563.8(2+)$ & $\begin{array}{l}\text { 87.1(imm Asp })^{+1}, 120.1(\mathrm{imm} \mathrm{Phe})^{+1}, 136.1(\mathrm{imm} . \mathrm{Tyr})^{+1} \\
\mathbf{2 0 7 . 1}\left(\mathrm{a}_{2}\right)^{+1}, \mathbf{2 3 2} .1\left(\mathbf{Y}_{2}\right)^{+1}, 235.1\left(\mathrm{~b}_{2}\right)^{+1}, 349.1\left(\mathrm{~b}_{3}\right)^{+1}, 450.2\left(\mathrm{Y}_{4}\right)^{+1}, \\
578.3\left(\mathrm{Y}_{5}\right)^{+1}, \mathbf{6 7 9 . 4}\left(\mathbf{Y}_{6}\right)^{+1}, \mathbf{8 9 2 . 5}\left(\mathbf{Y}_{\mathrm{s}}\right)^{+1}\end{array}$ \\
\hline FLPFQQFGR (S-16) & $570.3(2+)$ & $\begin{array}{l}70.1(\mathrm{imm} \text { Pro })^{+1}, 86.1(\mathrm{imm} \text { Ile })^{+1}, 120.1(\mathrm{imm} \mathrm{Phe})^{+1}, \mathbf{2 3 3 . 1}\left(\mathrm{a}_{2}\right) \\
{ }^{+1}, 261.2\left(\mathrm{~b}_{2}\right)^{+1}, \mathbf{4 4 0 . 2}\left(\mathrm{Y}_{7}\right)^{+2}, 635.3\left(\mathrm{Y}_{5}\right)^{+1}, \mathbf{7 8 2 . 5}\left(\mathrm{Y}_{6}\right)^{+1}, \mathbf{8 7 9 . 6}\left(\mathrm{Y}_{7}\right)^{+1}\end{array}$ \\
\hline SFIEDLLFNK (S-11) & $613.3(2+)$ & $\begin{array}{l}\text { 86.1(imm Ile })^{+1}, 120.1(\mathrm{imm} \mathrm{Phe})^{+1}, 129.1\left(\mathrm{Y}_{1}-\mathrm{H}_{2} \mathrm{O}\right)^{+1}, \mathbf{2 0 7 . 1 ( \mathbf { a } _ { 2 } )} \\
{ }^{+1,235.1}\left(\mathbf{b}_{2}\right){ }^{+1}, 358.2\left(\mathrm{Z}_{6}-\mathrm{NH}_{3}\right)^{+2}, 408.2\left(\mathrm{Y}_{3}\right)^{+1}, 749.4\left(\mathrm{Y}_{6}\right)^{+1}, \\
\mathbf{8 7 8 . 5}\left(\mathbf{Y}_{7}\right)^{+1}, 991.5\left(\mathbf{Y}_{8}\right)^{+1}\end{array}$ \\
\hline
\end{tabular}

retaining the charge. $\mathrm{Z}$, Ions that result from the cleavage of the $\mathrm{N}-\mathrm{C}$ bonds of a peptide backbone with the C-terminal fragments retaining the charge. $\mathrm{i}$, Ammonium ion is an internal fragment formed by a combination of a type $(\mathrm{C}-\mathrm{C}$ bond) and $\mathrm{Y}$ type $(\mathrm{C}-\mathrm{N}$ bond $)$ cleavage. Selected MRM transitions that were validated in non-spiked and spiked SARS-CoV-2 negative NP swab samples are in bold

ultra-performance liquid chromatography (UPLC). The best performance was achieved with $1.7-\mu \mathrm{m}$ UPLC C 18 column $(150 \times 2.1 \mathrm{~mm}, 1.7 \mu \mathrm{m}) \mathrm{kept}$ at $40{ }^{\circ} \mathrm{C}$, based on charged surface hybrid $(\mathrm{CSH})$ technology, applying water/acetonitrile acidic ( $1 \%$ formic acid) gradient and 10-min cycle time. Mobile phases were $1 \%$ formic acid in $\mathrm{H}_{2} \mathrm{O}$ (A) and $1 \%$ formic acid in $\mathrm{ACN}: \mathrm{H}_{2} \mathrm{O}(8: 2 \mathrm{v} / \mathrm{v}, \mathrm{B})$. The gradient profile was $100 \%$ A held for $0.3 \mathrm{~min}$, linearly decreased to $75 \%$ A over $4 \mathrm{~min}$, held for $0.5 \mathrm{~min}$, then decreased to $0 \% \mathrm{~A}$ over $2.5 \mathrm{~min}$, held for $1 \mathrm{~min}$, then increased to $100 \%$ A over $0.1 \mathrm{~min}$ and held for another $1.9 \mathrm{~min}$, for a total run time of $10 \mathrm{~min}$. The flow rate was $0.4 \mathrm{ml} / \mathrm{min}$ and the injection volume was $10 \mu$ l. The capillary voltage was adjusted to $0.6 \mathrm{kV}$ and the source temperature was set at $150{ }^{\circ} \mathrm{C}$. Intellistart software (part of MassLynx) was used for the determination and optimization of MRM transitions for the six commercial peptides. During the infusion of synthetic peptide standard solutions, cone voltages were adjusted for each peptide and collision energies were optimized for each fragment. Transitions for each peptide are shown in Fig. 1B. The instrument was programmed to acquire data in MRM mode.

\section{Results and discussion}

\section{LC-MS/MS(MRM) method development}

Our previous developed assay resulted in six unique SARSCoV-2 tryptic peptides markers, two derived from the $\mathrm{N}$ protein and four from the S protein [29]. Increasing the sensitivity and selectivity in complex matrices using mass 
AYNVTQAFGR (N-5)

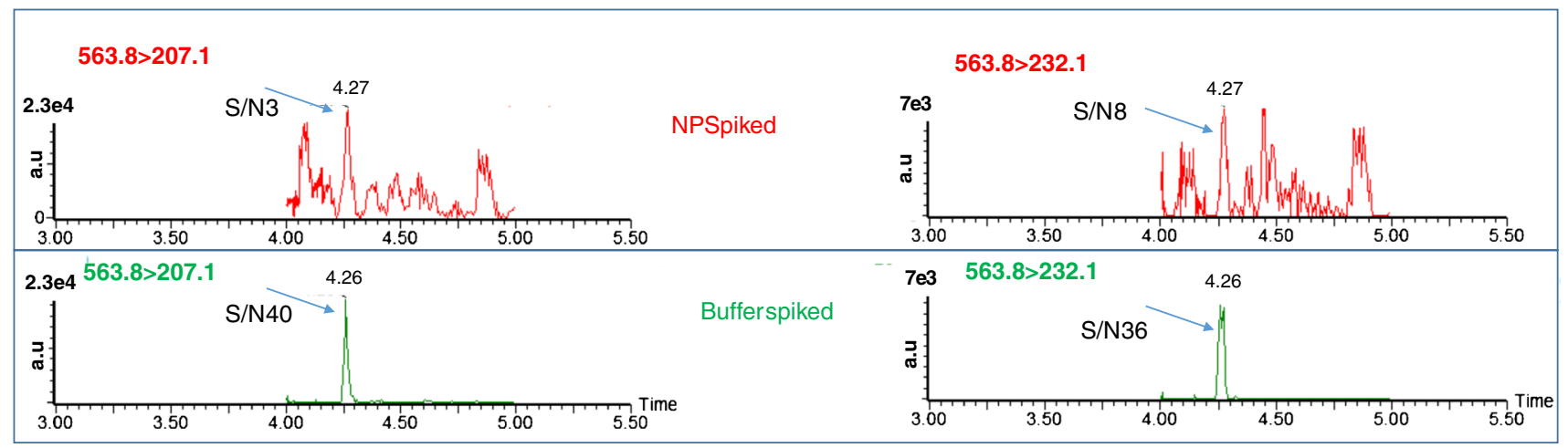

Fig. 2 LC-MS/MS (MRM) chromatograms of N-5 marker (2 MRM transitions) obtained from tryptic digest (without prior immunomagnetic capture) of $10^{5} \mathrm{PFU} / \mathrm{ml}$ SARS-CoV-2 spiked to ammonium bicarbonate and NP swab samples. The top frame contains chromatograms, painted in red, for two MRM transitions of N-5 marker

spectrometry analysis may be possible by a targeted MS/ MS-based MRM technique, using a triple quadrupole instrument that monitors specific fragmentation (MRM transitions) of selected peptide sequences. The MRM's targeted MS method was first evaluated using custom-made synthetic peptides, designed to correspond to the selected tryptic peptides. According to the European criteria [40], only two MRM transitions are required for molecule identification. However, to enhance the robustness of the assay in case of unexpected complex matrix interferences, 8-11 MRM transitions, extending from the multiple-charge molecular ions to their fragments' ions, were determined and optimized. A reproducible liquid-chromatographic method, which allows stable retention times of the markers in complex matrices, was also developed for reliable identification. The peptides' MRM transitions and chromatography are presented in Fig. 1. The limit of detection for each peptide was determined and all were found to be in the range of $10-100 \mathrm{pg} / \mathrm{ml}$.

\section{Sensitivity limitations due to matrix interferences}

Tryptic digestion was conducted as previously described $[29,38]$. To evaluate clinical matrix effects on SARSCoV-2 analysis based on LC-MS/MS(MRM) developed method, $50 \mathrm{mM}$ ammonium bicarbonate (herein termed "buffer") and NP negative swab samples in viral transport medium (VTM) were spiked with increasing concentrations of SARS-CoV-2 $\left(5 \times 10^{3}, 1 \times 10^{4}, 2.5 \times 10^{4}\right.$, $5 \times 10^{4}$, and $\left.1 \times 10^{5} \mathrm{PFU} / \mathrm{ml}\right)$. The samples were heated for virus inactivation and denaturation, trypsin-digested for $120 \mathrm{~min}$, and analyzed by LC-MS. Simultaneously, negative control samples, without the virus, were similarly derived from tryptic digest of spiked NP specimen. The bottom frame contains chromatograms, painted in green, for two MRM transitions of N-5 marker derived from tryptic digest of the virus in ammonium bicarbonate solution. The blue arrow pointed the chromatographic peak for $\mathrm{N}-5$ marker

processed. All reactions were performed in triplicates. Figure 2 demonstrates comparative LC-MS/MS(MRM) chromatograms of a representative marker (N5) obtained from tryptic digest of SARS-CoV-2 spiked into buffer or NP negative swab samples. The peak intensities of MRM transitions were similar in both samples, buffer and NP, indicating comparable tryptic digestion efficiency; however, the background noise was significantly higher in the NP sample. Therefore, the reduction in $\mathrm{S} / \mathrm{N}$ ratios resulted in reduced sensitivity of more than an order of magnitude in NP swab specimens as compared with buffer samples (Table 1). In addition, as a result of background peaks in NP negative control samples, some MRM transitions were interrupted, i.e., all MRM transitions of S-18 marker were interfered; thus, this marker could not be detected. This high background noise in ESI-MS is contributed by secretions originating from the nose and throat (which can create different backgrounds among individuals) and/or a constant background noise derived from the VTM. There are diverse formulations of VTM, most of which are protein-rich $(0.5-10 \mathrm{mg} / \mathrm{ml})$, e.g., albumin or serum, usually in a buffer salt solution [41]. Inorganic salts are known for their signal suppression in ESI, while the presence of high concentrations of protein enhances the background noise derived from tryptic digestion of a VTM containing the clinical sample. It should be taken into consideration that different VTM formulations can have different impacts on assay performance. Therefore, separation of the virus from the specimen medium prior to its tryptic digestion and LC-MS/MS(MRM) analysis is essential for a sensitive, robust, effective, and applicable assay, regardless of the VTM formulation or variable interferences originating in clinical samples. 


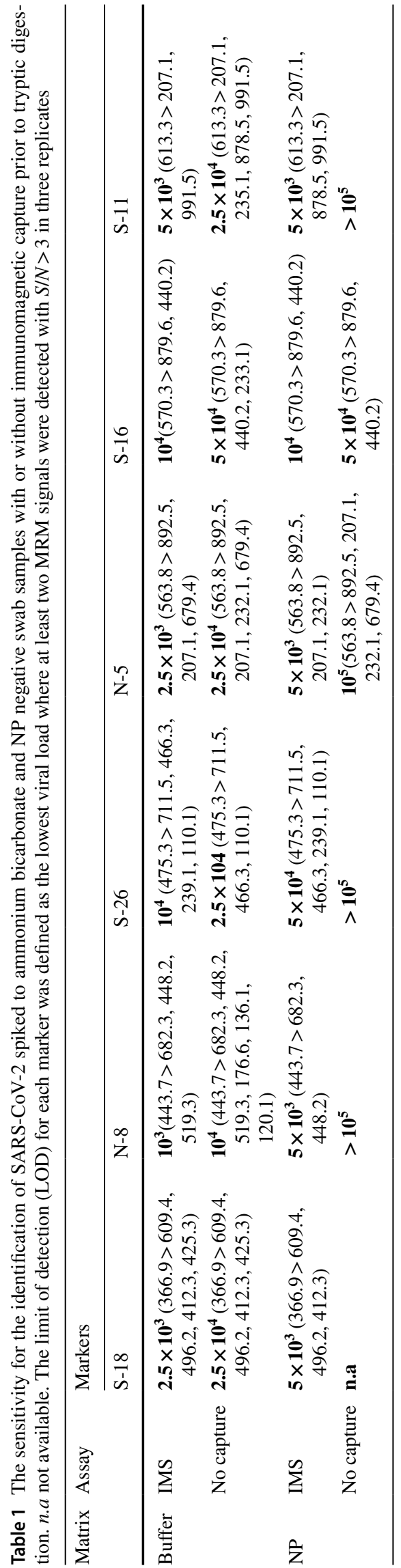

Development of immunomagnetic beads separation method

\section{Capture of SARS-CoV-2 from buffer}

Immunomagnetic beads coated with rabbit polyclonal IgG- $\alpha$-SARS-CoV-2 ("R606") or IgG- $\alpha$-Spike ("R15") Abs were prepared, and their efficiency was evaluated in capturing purified S-protein or entire SARS-CoV-2 viruses from buffer. Higher capture efficiencies of purified S-protein were achieved using R15 compared to R606 ( $\sim 100 \%$ vs. $\sim 60 \%$, respectively), while the opposite was observed for capturing the entire SARS-CoV-2, in which R606 obtained $\sim 100 \%$ efficiency, as well as higher precision values. This higher R606 capture efficiency may be a result of a variety of Abs against other epitopes (in addition Abs against the spike protein) improving viral capture capability. Therefore, R606 was selected for further evaluation.

In addition, to optimize the capture conditions, several bead diameters, capturing protocols (sequential vs. "all in one," see "Materials and methods") and washing procedures were evaluated and optimized as well. The final process included binding the biotinylated-R606 to the streptavidincoated $1-\mu \mathrm{m}$ beads, washing of the residual unbound Abs, and capturing the viruses from the 1-ml sample, followed by serial washes to a final volume of $100 \mu \mathrm{l}$, achieving a tenfold concentration compared to the original sample.

To assess the efficiency of SARS-CoV-2 enrichment using the optimized conditions, the assay was conducted in triplicates with SARS-CoV-2 spiked to buffer, with or without immunomagnetic enrichment. Virus enrichment was performed from an initial volume of $1 \mathrm{ml}$ containing $5 \times 10^{4} \mathrm{PFU} / \mathrm{ml}$ SARS-CoV-2 in buffer. Beads with the attached virus were then resuspended in $0.1 \mathrm{ml}$ buffer for tryptic digestion. For comparison, tryptic digestion was performed to a $0.1-\mathrm{ml}$ sample containing the same virus concentration without capturing. Theoretically, maximum capture efficiency allows a tenfold increase in markers' peak intensity in comparison to markers' intensity derived from tryptic digestion without prior enrichment. Figure 3 presents the high enrichment efficiency, estimated as a 8to tenfold increase.

\section{SARS-CoV-2 enrichment from NP specimens}

Enriching the virus from complex matrices requires considering additional parameters, as non-specific binding of matrix substances to the beads or the decrease of capture efficiency as a result of matrix interferences. To minimize the decrease in capture efficiency due to matrix interferences, several dilutions of NP specimens spiked with $5 \times 10^{4}$ 
Fig. 3 Immunomagnetic beads capture efficiency from buffer solution. Comparison between peak intensities of the six tryptic peptides obtained with or without prior immunomagnetic capture (R606). The capture was performed from $1 \mathrm{ml}$ of $5 \times 10^{4} \mathrm{PFU} / \mathrm{ml} \mathrm{SARS}-\mathrm{CoV}-2$ in ammonium bicarbonate. Its tryptic digestion was done in $0.1 \mathrm{ml}$ ammonium bicarbonate buffer. Maximum capture efficiency will allow a tenfold increase in peak intensity. Error bars indicate the coefficient of variation percent $(\% \mathrm{CV})$

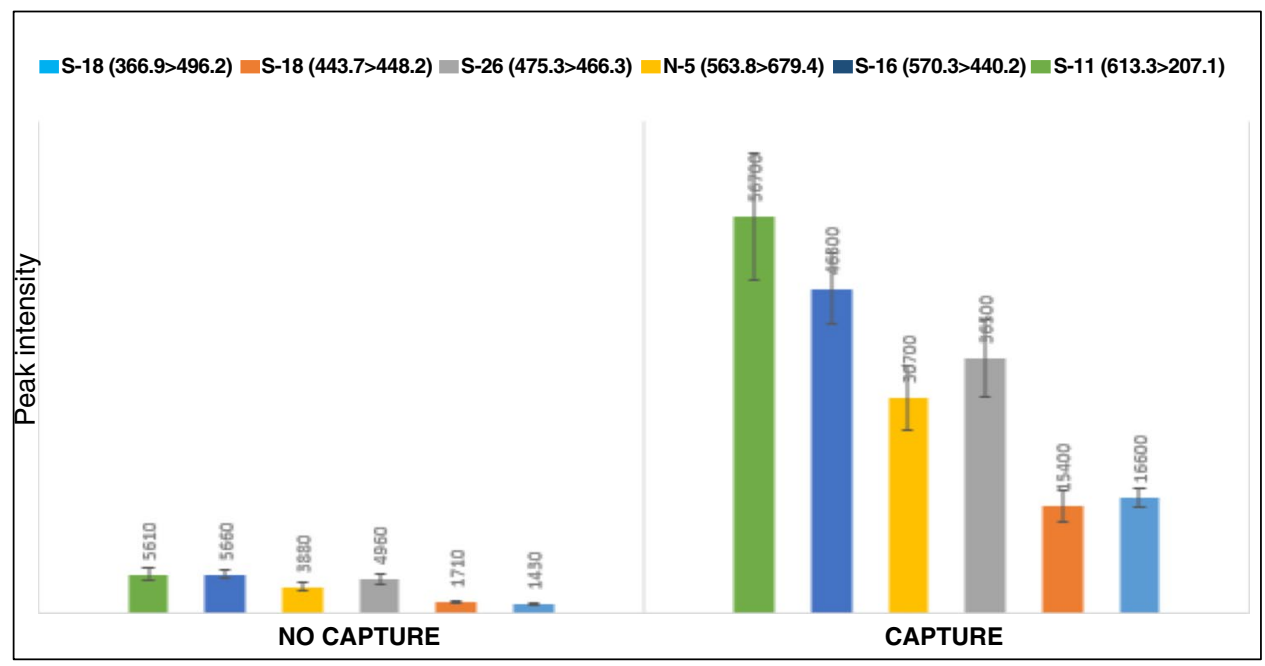

PFU/ml SARS-CoV-2 were evaluated (no dilution, 1:1 and 1:2, NP sample:buffer). Best performances were obtained with no prior dilution.

To evaluate virus enrichment from NP samples on assay's sensitivity, SARS-CoV-2 were spiked into NP samples to a concentration of $5 \times 10^{4} \mathrm{PFU} / \mathrm{ml}$. The assay was conducted with or without immunomagnetic capture prior to tryptic digestion. Figure 4 demonstrates a significant increase in $S / N$ values as a result of virus purification from the clinical medium prior to its tryptic digestion. Marker N5 was hardly detected directly in NP specimen (only one MRM transition with $S / N=3$ ), while the virus enrichment from these challenging matrices enabled the identification of this marker according to $2 \mathrm{MRM}$ transitions with nearly 50 -fold $\mathrm{S} / \mathrm{N}$ enhancement due to the combination of sample concentration (tenfold) and background noise reduction ( fivefold).

\section{Assay performance}

\section{MRM transitions' adjustment for NP matrix}

Despite the significant improvement in background noise as a result of the use of the IMS technique, there may still be interfering peaks that can lead to misleading identification. Therefore, the protocol was performed in triplicate using negative NP specimens previously pooled from two naïve individuals. All MRM transitions for each of the six markers were evaluated for background noise level and interfering peaks originating from assay components and matrix residuals. The interrupted MRM transitions were excluded from the MS method to avoid false positive results. As can be seen in Fig. 1B, the number of peptide markers with their selected MRM transitions (in bold) is by far more than required by the European Commission for unambiguous identification (one unique marker with two MRM transitions) [40]. These MRM transitions were used for further validation.

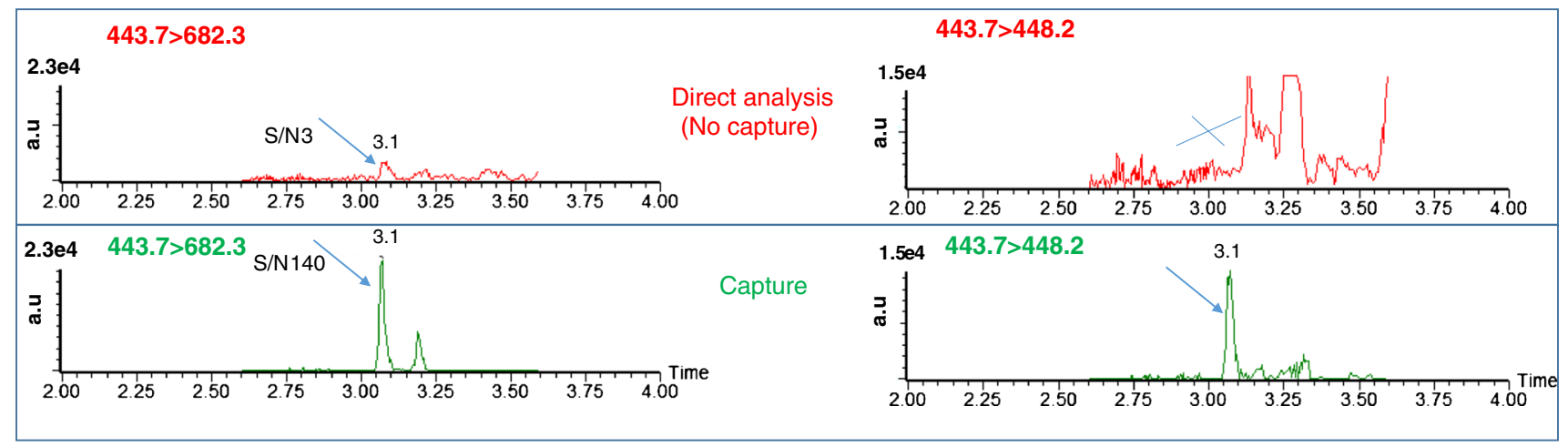

Fig. 4 LC-MS/MS(MRM) chromatograms of marker N-8 (GFYAEGSR) by two MRM transitions, obtained from tryptic digest of $5 \times 10^{4} \mathrm{PFU} / \mathrm{ml}$ SARS-CoV-2 spiked into NP specimens, with or without prior IMS of the virus. Top frame, two MRM transitions chromatograms, painted in red, of N-8 marker derived from direct analysis of NP specimen (without capture). Bottom frame, chromatograms, painted in green, containing the same transitions after IMS 
Fig. 5 Assay's linearity, the linearity of the six SARSCoV-2 markers, derived from spiked NP swab samples. Each marker is marked with a dot in a different color. The identity of the markers is displayed in Fig. 1. Tryptic digest reactions with prior virus enrichment were performed for SARSCoV-2 - spiked NP samples in the range of $2.5 \times 10^{3}-10^{5}$ $\mathrm{PFU} / \mathrm{ml}$. PFU, plaque-forming unit. The blue arrow marks the chromatographic peak for $\mathrm{N}-8$ marker. Error bars indicate the coefficient of variation percent $(\% \mathrm{CV})$

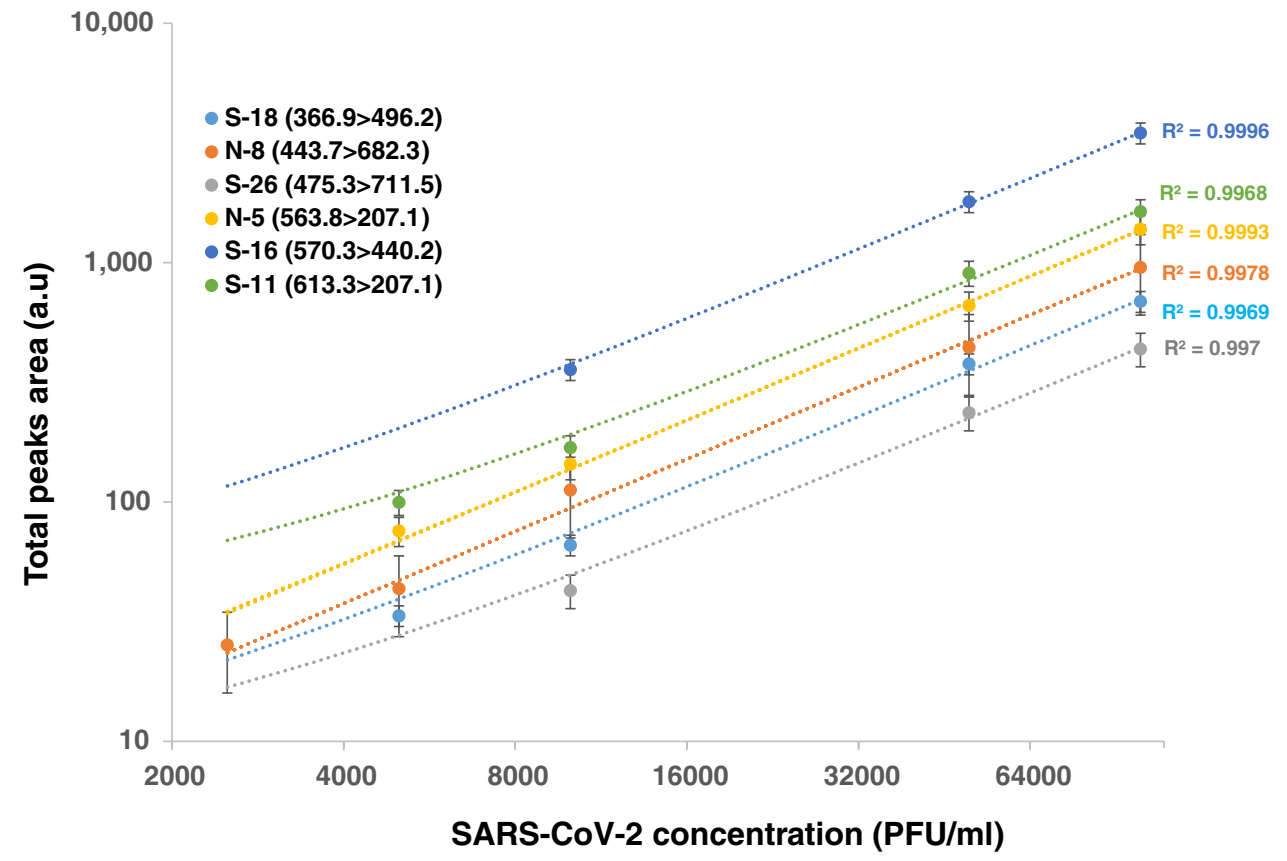

\section{Assay sensitivity, linearity, precision, and accuracy}

To assess the diagnostic performance of the IMS-based assay, SARS-CoV-2 was spiked into buffer or pooled NP samples (obtained from ten negative individual human samples). Assays were performed in 3-5 replicates at concentrations of $0,2.5 \times 10^{3}, 5 \times 10^{3}, 10^{4}, 5 \times 10^{4}$, and $10^{5} \mathrm{PFU} / \mathrm{ml}$ SARSCoV-2. The spiked samples were processed according to the described protocol. For comparison, tryptic digestion was performed directly on the same virus concentrations, spiked into buffer or pooled NP samples, without prior enrichment.

The limit of detection (LOD) for each marker was defined as the lowest viral load where at least two MRM signals were detected with $S / N>3$ in 3 replicates. Table 1 summarizes the LODs for SARS-CoV-2 markers from buffer and NP spiked specimens with or without IMS prior to tryptic digestion. The IMS protocol, conducted in buffer, enabled the identification of $10^{3} \mathrm{PFU} / \mathrm{ml} \mathrm{SARS-CoV-2} \mathrm{(by}$ the N8 marker with three MRM transitions) compared to $10^{4} \mathrm{PFU} / \mathrm{ml}$ SARS-CoV-2 without viral enrichment. To evaluate assay sensitivity in clinical samples, the appropriate controls were virus spiked to negative NP swab specimens, since NP matrices contain interfering contaminates originating from both viral transport media and biological naso-pharyngeal materials. The enrichment protocol, from NP specimen, enabled the identification of $5 \times 10^{3} \mathrm{PFU} /$ $\mathrm{ml}$ SARS-CoV-2 (according to four markers, S-18, N-8, $\mathrm{N}-5$, and S-11, each with at least two MRM transitions). Comparison of markers' sensitivity in NP sample, without prior isolation of the virus from the matrix, showed a lower sensitivity of more than one order of magnitude, while S-18 identification was not even possible. Comparing markers' sensitivity, obtained for SARS-CoV-2 enrichment from NP and buffer samples, revealed comparable sensitivity for S-16 and S-11 markers and reduced sensitivity in enrichment from NP matrices for the four additional markers (2-fivefold), as a result of higher chromatographic noise levels. Recently, J. Saadi et al. reported on similar sensitivity for SARS-CoV-2 spiked to several viral transport media [25]. In this study, virus enrichment was performed by methanol precipitation, which is not selective and may be affected by the variability of NP samples.

The linearity of the IMS-based assay in spiked NP swab samples is demonstrated in Fig. 5 for the six peptides over a concentration range of almost two orders of magnitude $\left(2.5 \times 10^{3}-1 \times 10^{5} \mathrm{PFU} / \mathrm{ml}\right)$. The $R^{2}$ values obtained for linear curves were $\geq 0.997$. The calculated precision values, for pooled NP samples spiked with SARS-CoV-2, were in the range of $0.3-18 \%$ (RSD) except for $27 \%$ obtained for the LOD's concentration $\left(2.5 \times 10^{3} \mathrm{PFU} / \mathrm{ml}\right)$ of $\mathrm{N}-8$ marker.

The accuracy of the assay was evaluated using recalculated SARS-CoV-2 concentration values $\left(2.5 \times 10^{3}\right.$, $5 \times 10^{3}, 10^{4}, 5 \times 10^{4}$, and $10^{5} \mathrm{PFU} / \mathrm{ml}$ ) based on calibration curves for the six peptides, prepared according to the assay's protocol with NP swab specimens spiked with SARS-CoV-2 in the range of $2.5 \times 10^{3}$ to $10^{5} \mathrm{PFU} / \mathrm{ml}$. The accuracy (\% error) of the method for all markers was lower than $20 \%$, while the best accuracy $(<3 \%)$ was obtained for S-16 marker. 


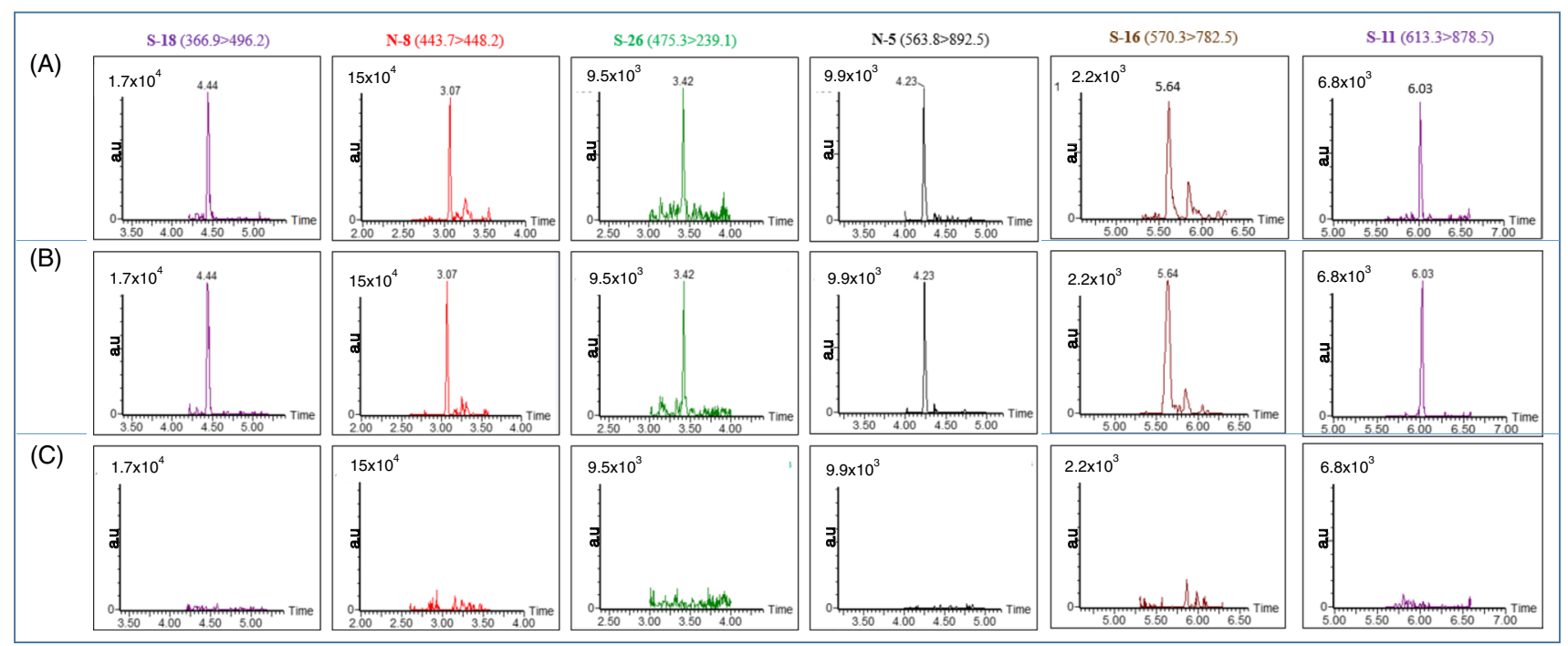

Fig. 6 Assay validation in different individuals' NP spiked specimens. LC-MS/MS(MRM) chromatograms of the six markers: (A) typical NP negative swab sample spiked with SARS-CoV-2 $\left(5 \times 10^{4}\right.$ PFU/ml). (B) Positive control: ammonium bicarbonate buffer spiked

\section{Retention time stability}

Retention time stability is of great importance as it is an essential means for marker identification. Keeping high reproducibility of marker retention times is especially challenging in complex matrices that do not undergo sample pretreatment. Capturing the virus from NP matrices allows preserving high retention time reproducibility. Retention time variations were evaluated for the six markers, derived from different concentrations of SARS-CoV-2 spiked to buffer and negative swab NP samples $(n=20)$, which were threated and injected at different days (Table S1). Low run-to-run variations for the six markers, $\pm 0.01 \mathrm{~min}- \pm 0.05 \mathrm{~min}$, were observed indicating the chromatographic stability of the analytical method.

\section{Assay validation}

The assay was validated using 29 different NP swab specimens, previously determined negative by PCR. For evaluating the method's performance, 10 of the NP specimens were used as negative controls, while nineteen samples were spiked with SARS-CoV-2 to final concentration of $5 \times 10^{4}$ $\mathrm{PFU} / \mathrm{ml}$. Since the LODs of the six markers in NP-spiked specimens were found to be in the range of $5 \times 10^{3}-5 \times 10^{4}$ $\mathrm{PFU} / \mathrm{ml}$ SARS-CoV-2, the higher concentration $\left(5 \times 10^{4}\right.$ $\mathrm{PFU} / \mathrm{ml}$ ) was selected for validation to assess all the six markers. To determine the assay's efficiency in NP-spiked samples, the buffer was spiked with $5 \times 10^{4} \mathrm{PFU} / \mathrm{ml}$ SARSCoV-2 for comparison as a positive control. SARS-CoV-2 was unambiguously identified in all 19 spiked NP samples, with SARS-CoV-2 $\left(5 \times 10^{4} \mathrm{PFU} / \mathrm{ml}\right)$. (C) Negative control: naive NP specimen. Each chromatogram represents a validated MRM transition (peak intensity)

while no false positive results were observed in any of the 10 negative control samples. Figure 6A illustrates representative results for MRM transitions of all 6 selected markers, after capturing the virus from NP specimen spiked with $5 \times 10^{4} \mathrm{PFU} / \mathrm{ml}$ SARS-CoV-2. A positive control buffer sample spiked with the same virus concentration is presented in Fig. 6B, while negative control (naive NP swab specimen), lacking SARS-CoV-2 markers, is shown in Fig. 6C. The identification of SARS-CoV-2 was enabled based on its six unique markers owing the expected retention times and the NP-designed MRM transitions panel. Peak intensities in NP-spiked samples after IMS were similar to buffer spiked samples, demonstrating the high capture efficiency from complex matrices. The assay's reproducibility was evaluated by calculating the precision (relative standard deviation) values for peak intensities, of all selected MRM transitions for each marker, obtained from 19 distinct spiked NP specimens. The MRM transitions' peak ratios, defined for each peptide marker, were calculated with their standard deviation. The precision values of peak intensities and MRM transition ratios were less than $30 \%$ (Table 2). MRM transitions' peak ratios were consistent with the ratios obtained from a buffer spiked with the same SARS-CoV-2 concentrations (positive control samples).

\section{Criteria for SARS-CoV-2 identification}

Even though one unique marker is sufficient to provide a reliable basis for virus identification, a panel of six unique and specific peptide markers, originating from 


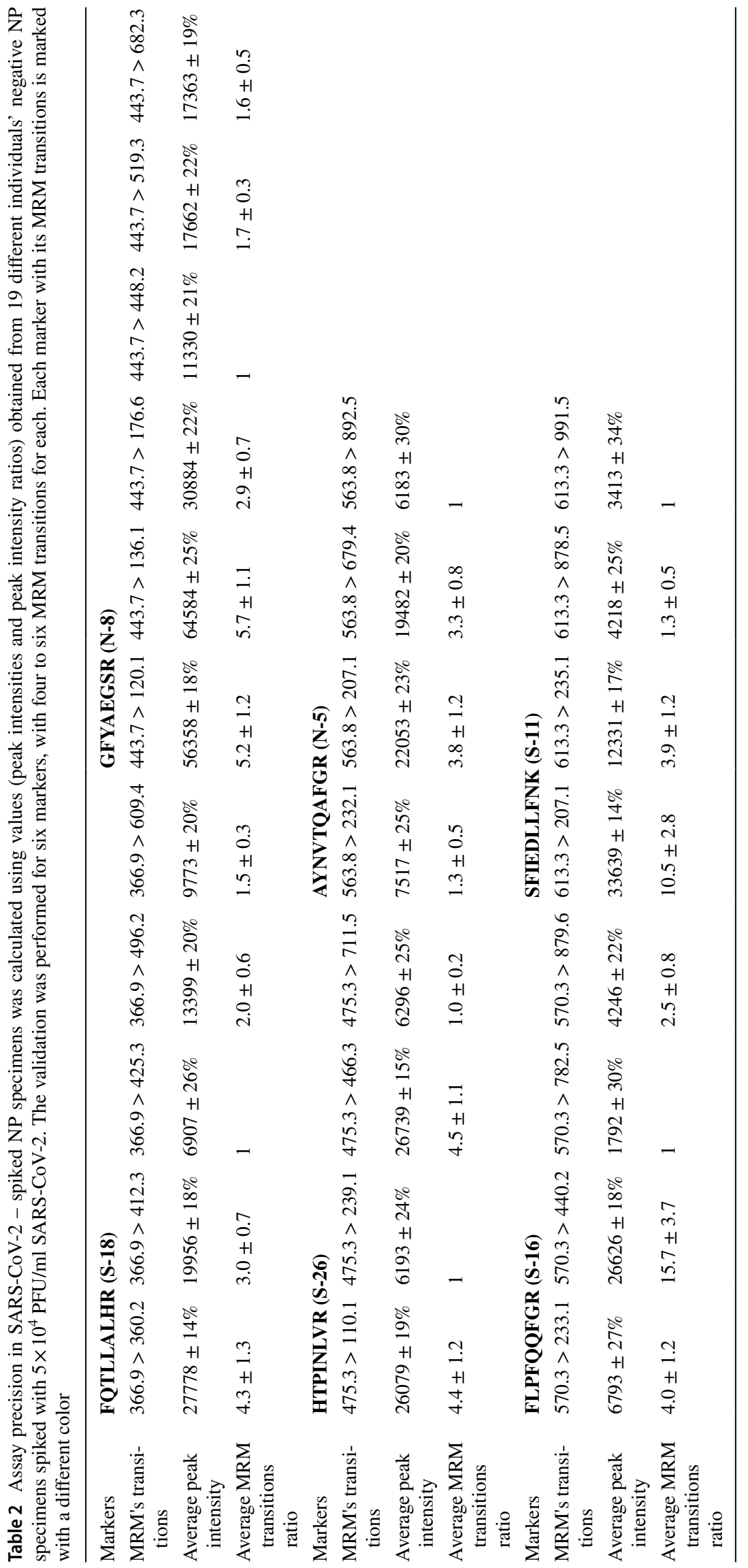


distinct regions in two different viral proteins, was established [29]. Therefore, there is a high probability that virus detection will not be abolished, even in case of mutations occurring during the spread of the virus, virus fragmentation, or unexpectedly challenging matrices. Based on our finding, we outline criteria for unambiguous identification of SARS-CoV-2 in NP swab specimens: (a) one marker, as a minimum, with at least two MRM transitions, each with $S / N>3$, having a suitable MRM peak ratio as the positive control assay performed in a spiked buffer or negative swab NP sample (Table 2); (b) chromatographic retention times correlating to the positive control (Table S1).

\section{Analysis of clinical samples}

The assay was further evaluated in a real-life setting using authentic clinical NP swab specimens, previously diagnosed by RT-qPCR. A total of 26 NP swab specimens, 13 testing negative and 13 testing positive, were examined using the developed assay. Table 3 summarizes the results for marker

Table 3 Clinical sample analysis. SARS-CoV-2 markers detected and identified in NP swab specimens by LC-MS/MS(MRM) analysis. At least one marker with two MRM transitions, positive control-compatible MRM's ratio, and r.t are required for marker's identification

\begin{tabular}{|c|c|c|c|}
\hline NP specimens & $\mathrm{PCR}(\mathrm{Ct})$ & Markers (MRM transitions) & r.t $(\min )^{\mathrm{a}}$ \\
\hline 1 & $+(16.3)$ & $\begin{array}{l}\mathbf{S}-18(366.9>609.4,366.9>496.2), \mathbf{N}-8(443.7>682.3 \\
443.7>519.3,443.7>448.2,443.7>176.6), \mathbf{N}-5 \\
(563.8>892.5,563.8>207.1), \mathbf{S}-16(570.3>879.6 \\
570.3>440.2)\end{array}$ & $4.43(\mathrm{~S}-18), 3.05(\mathrm{~N}-8), 4.22(\mathrm{~N}-5), 5.56(\mathrm{~S}-16)$ \\
\hline 2 & $+(21.0)$ & $\begin{array}{c}\text { S-18 }(366.9>609.4,366.9>496.2), \mathbf{N}-8(443.7>682.3 \\
443.7>448.2), \mathbf{S}-16(570.3>879.6,570.3>440.2)\end{array}$ & $4.42(\mathrm{~S}-18), 3.06(\mathrm{~N}-8), 5.57(\mathrm{~S}-16)$ \\
\hline 3 & $+(15.7)$ & $\begin{array}{l}\text { S-18 }(366.9>609.4,366.9>496.2), \mathbf{N}-8(443.7>682.3 \\
443.7>519.3,443.7>448.2,443.7>176.6), \mathbf{S}-26 \\
(475.3>711.5,475.3>466.3,475.3>239.1) \\
\mathbf{N - 5}(563.8>892.5,563.8>207.1,563.8>679.4 \\
563.8>232.1), \mathbf{S}-16(570.3>879.6,570.3>440.2 \\
570.3>782.5)\end{array}$ & $\begin{array}{l}4.41(\mathrm{~S}-18), 3.06(\mathrm{~N}-8), 3.40(\mathrm{~S}-26), 4.22(\mathrm{~N}-5), 5.55 \\
\quad(\mathrm{~S}-16)\end{array}$ \\
\hline 4 & $+(17.4)$ & $\begin{array}{c}\text { S-18 }(366.9>609.4,366.9>496.2), \mathbf{N}-8(443.7>682.3 \\
443.7>519.3), \text { S-16 }(570.3>879.6,570.3>440.2)\end{array}$ & $4.42(\mathrm{~S}-18), 3.06(\mathrm{~N}-8), 5.56(\mathrm{~S}-16)$ \\
\hline 5 & $+(19.9)$ & - & - \\
\hline 6 & $+(17.9)$ & $\begin{array}{c}\text { S-18 }(366.9>609.4,366.9>496.2,366.9>412.3), \\
\text { N-8 }(443.7>682.3,443.7>519.3,443.7>448.2), \\
\text { N-5 }(563.8>892.5,563.8>207.1,563.8>679.4, \\
563.8>232.1), \text { S-16 }(570.3>879.6,570.3>440.2, \\
570.3>782.5), \text { S-11 }(613.3>207.1,613.3>991.5)\end{array}$ & $\begin{array}{l}4.42(\mathrm{~S}-18), 3.06(\mathrm{~N}-8), 4.22(\mathrm{~N}-5), 5.56(\mathrm{~S}-16), 6.01 \\
\quad(\mathrm{~S}-11)\end{array}$ \\
\hline 7 & $+(19.2)$ & $\begin{array}{l}\text { S-18 }(366.9>609.4,366.9>496.2), \mathbf{N}-8(443.7>682.3 \\
443.7>519.3), \mathbf{N}-5(563.8>892.5,563.8>207.1 \\
563.8>679.4), \mathbf{S - 1 6}(570.3>879.6,570.3>440.2 \\
570.3>782.5)\end{array}$ & 4.42(S-18), $3.06(\mathrm{~N}-8), 4.22(\mathrm{~N}-5), 5.56(\mathrm{~S}-16)$ \\
\hline 8 & $+(19.2)$ & $\begin{array}{c}\mathbf{S - 1 8}(366.9>609.4,366.9>496.2,366.9>425.3), \mathbf{N - 8} \\
(443.7>682.3,443.7>519.3,443.7>176.6), \mathbf{N}-\mathbf{5} \\
(563.8>892.5,563.8>207.1,563.8>232.1)\end{array}$ & $4.42(\mathrm{~S}-18), 3.06(\mathrm{~N}-8), 4.23(\mathrm{~N}-5)$ \\
\hline 9 & $+(19.8)$ & $\begin{array}{l}\text { S-18 }(366.9>609.4,366.9>496.2), \mathbf{N - 8}(443.7>682.3 \\
\quad 443.7>519.3)\end{array}$ & 4.41(S-18), $3.06(\mathrm{~N}-8)$ \\
\hline 10 & $+(20.8)$ & $\begin{array}{l}\text { S-18 }(366.9>609.4,366.9>496.2,366.9>412.3, \\
\quad 366.9>360.2), \mathbf{N - 8}(443.7>682.3,443.7>448.2), \mathbf{N}-5 \\
(563.8>892.5,563.8>207.1), \mathbf{S}-\mathbf{1 1}(613.3>991.5, \\
613.3>878.5)\end{array}$ & $4.41(\mathrm{~S}-18), 3.06(\mathrm{~N}-8), 4.22(\mathrm{~N}-5), 6.01(\mathrm{~S}-11)$ \\
\hline 11 & $+(20.5)$ & - & - \\
\hline 12 & $+(20.0)$ & $\begin{array}{l}\text { S-18 }(366.9>609.4,366.9>496.2,366.9>412.3), \\
\quad \text { N-8 }(443.7>682.3,443.7>448.2,443.7>176.6), \\
\text { N-5 }(563.8>892.5,563.8>207.1,563.8>679.4, \\
563.8>232.1), \text { S-16 }(570.3>879.6,570.3>440.2, \mathbf{S - 1 1} \\
(613.3>207.1,613.3>991.5,613.3>235.1)\end{array}$ & $\begin{array}{l}4.42(\mathrm{~S}-18), 3.06(\mathrm{~N}-8), 4.22(\mathrm{~N}-5), 5.58(\mathrm{~S}-16), 6.01 \\
\quad(\mathrm{~S}-11)\end{array}$ \\
\hline 13 & $+(20.0)$ & $\begin{array}{l}\mathbf{N}-8(443.7>448.2,443.7>519.3,443.7>176.6), \mathbf{N}-5 \\
\quad(563.8>892.5,563.8>232.1)\end{array}$ & $3.06(\mathrm{~N}-8), 4.22(\mathrm{~N}-5)$ \\
\hline $14-26$ & $-(>40.0)$ & - & - \\
\hline
\end{tabular}

${ }^{a}$ Retention time accuracy $< \pm 0.05 \mathrm{~min}$ 
Fig. 7 LC-MS/MS(MRM) identification of SARS-CoV-2 in clinical sample. An example for the identification of a specific marker (AYNVTQAFGR, $\mathrm{N}-5$ ) derived from immunomagnetic capture of the virus from swab NP individual, followed by tryptic digestion. (A) LCMS/MS(MRM) chromatograms (two MRM transitions) of positive NP specimen. (B) LC-MS/ MS(MRM) chromatograms (two MRM transitions) of $10^{5}$ SARS-CoV-2 spiked to negative NP specimen (positive control). (C) LC-MS/MS(MRM) chromatograms (two MRM transitions) of negative NP specimens (negative control)

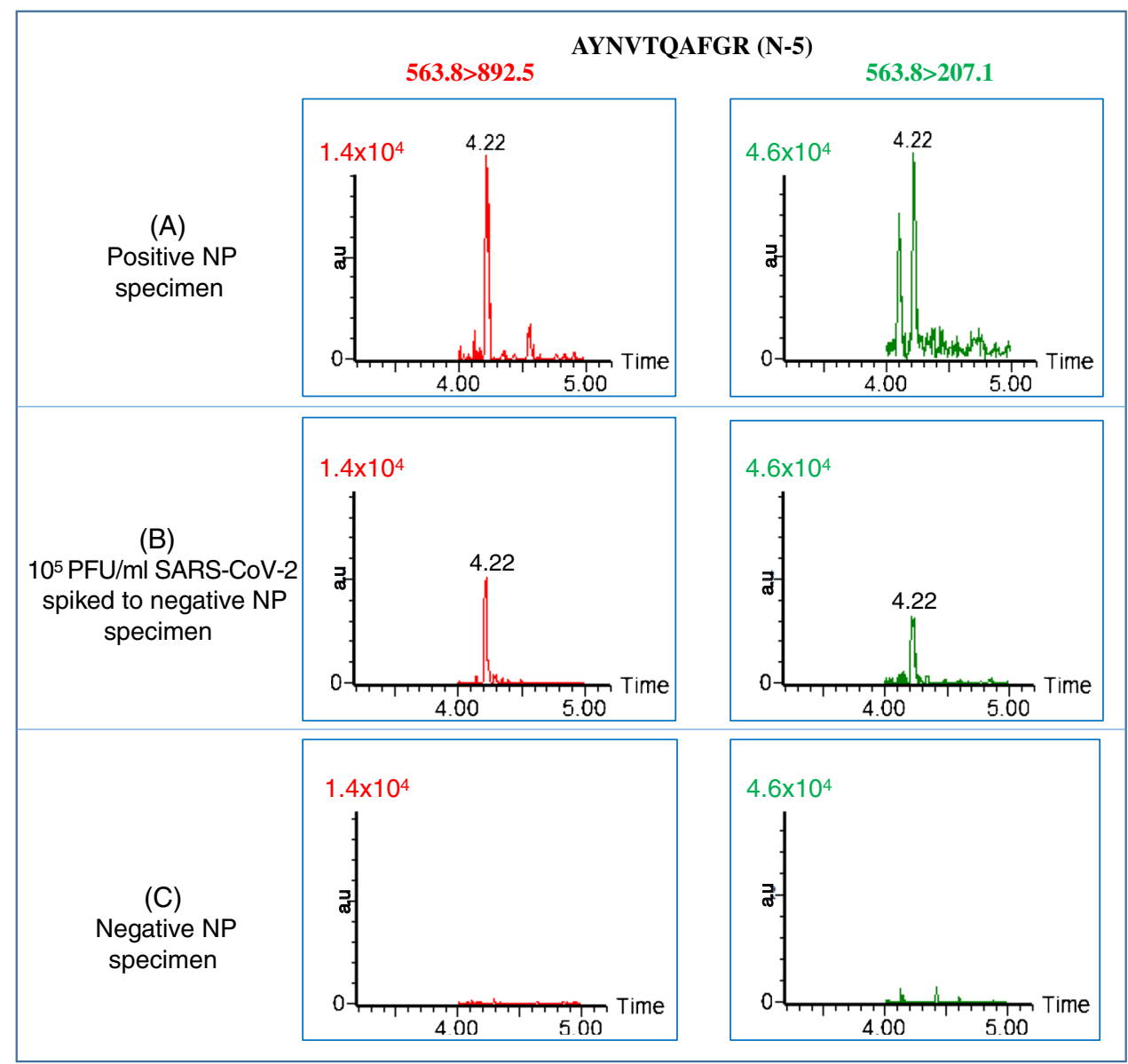

identification in NP swab samples using LC-MS/MS(MRM) analysis. Figure 7 demonstrates the identification of representative SARS-CoV-2-specific marker (N-5) in a positive NP specimen (Fig. 7A), as well as in SARS-CoV-2 spiked into negative NP swab specimen (Fig. 7B). This marker is absent from a negative NP sample (Fig. 7C). Similarly, the presence of SARS-CoV-2 was confirmed in 11 specimens which previously tested positive with $\mathrm{Ct}$ values in the range of 15.7-21. In these samples, the virus was identified based on 2 to 5 identified markers with two or more previously validated MRM transitions, each with $S / N>3$, having suitable MRM peak ratios and chromatographic retention times correlating to the positive control. In two of the thirteen NP specimens reported as positive (Ct values of 19.9 and 20.5), the virus was not identified based on the presented assay. Discrepancies with RT-qPCR are possibly due the fundamentally different viral constituent assayed by MS and PCR - the RT-qPCR identifies RNA while the LC-MS detects and identifies proteins. The presence of one does not necessarily mean the presence of the other, since clinical samples may contain residual viral genetic material and not the intact virus [12]. The virus concentrations in the tested clinical samples were evaluated by comparison with a standard curve created by negative NP samples spiked with known concentrations of SARS-CoV-2. The tested clinical samples were found to contain virus calculated concentrations of $5 \times 10^{3}-2 \times 10^{5} \mathrm{PFU} / \mathrm{ml}$. In addition, it has been shown that all 13 RT-qPCR-negative NP samples did not contain any marker of SARS-CoV-2; thus, no false positive result was observed. The proposed assay achieved $92 \%$ (24/26) concordance with RT-qPCR assay.

\section{Conclusions}

In this study, we developed a sensitive, reliable, and highly specific approach for the identification of six SARS-CoV-2 unique markers, derived from Spike (S) and Nucleocapsid (N) proteins, based on the combination of virus selective enrichment from nasopharyngeal (NP) specimens and targeted LC-MS/MS(MRM) analysis. A sensitive and selective LC-MS/MS(MRM) analysis method was developed for the identification of the selected tryptic peptide markers. A virus enrichment method from clinical challenging matrices was established based on IMS of SARS-CoV-2, prior to its tryptic digestion, using magnetic beads coated with polyclonal IgG- $\alpha$-SARS-CoV-2 antibodies. We consider the sample preparation protocol to be straightforward, consisting 
of virus capture at $37{ }^{\circ} \mathrm{C}$ for $30 \mathrm{~min}$ followed by a washing series, heating for virus deactivation and denaturation followed by $2 \mathrm{~h}$ of tryptic digestion and $10 \mathrm{~min}$ of LC-MS/ MS(MRM) analysis. The overall process takes about $3 \mathrm{~h}$. While sample preparation is done simultaneously on multiple samples, sample analysis using LC-MS is done sequentially. Therefore, shortening LC-MS/MS(MRM) analysis in the future may significantly shorten the entire process time in case of numerous samples. This study presents a comprehensive evaluation of the effect of NP swab matrices on virus direct diagnosis and the contribution of the IMS technique, combined with MS-based MRM analysis, to improving assay sensitivity. We suggest that this Ab-based approach, in contrast to other virus non-selective enrichment methods, can deal with different challenging clinical matrices. This approach both increased sample concentration and significantly reduced matrix background noise. These resulted in an improved sensitivity by more than an order of magnitude, for the identification of SARS-CoV-2 from buffer $\left(1 \times 10^{3} \mathrm{PFU} / \mathrm{ml}\right)$ and NP specimens $\left(5 \times 10^{3}\right.$ $\mathrm{PFU} / \mathrm{ml}$ ), compared to direct determination of the virus from NP specimens. Additional sensitivity improvement may be achieved by performing the IMS from larger volumes of NP specimens. The assay was verified in 19 diverse naive NP specimens spiked with SARS-CoV-2 and proved to be linear, quantitative, and reproducible. Finally, the assay was successfully applied in clinical NP samples $(n=26)$ predetermined by RT-qPCR as positive or negative, achieving $92 \%$ concordance with the current gold standard assay.

The assay described here is highly reliable, specific, and sensitive, and thus potentially may serve as a complementary assay to RT-qPCR. This assay has the potential to be further extended to additional relevant clinical matrices. In addition, the IMS concept, which enables selective virus capturing from matrix interferences to MS-based analysis, may be applied as a sensitivity enhancement step in diagnostic assays for the identification of other viruses and pathogens.

Supplementary Information The online version contains supplementary material available at https://doi.org/10.1007/s00216-021-03831-5.

Acknowledgements The authors would like to thank Dr. Ohad Mazor and Dr. Eytan Elhanany for their fruitful remarks and help in reviewing of this manuscript. We thank Ron Alcalay for IgG purification.

Funding This study was funded by the Israel Institute for Biological Research (IIBR).

\section{Declarations}

Conflict of interest The authors declare no competing interests.

Consent for publication All the authors read and approved of the final manuscript.
Human samples Leftovers of pre-existing samples were used and deidentified. This work was therefore determined to be a research not involving human subjects.

Animals Treatment of animals was in accordance with regulations outlined in the U.S Department of Agriculture (USDA) Animal Welfare Act, and the conditions specified in the Guide for Care and use of Laboratory Animals (National Institute of Health, 2011). Animal studies were approved by the local ethical committee on animal experiments (protocol number $\mathrm{Rb}-04-20$ ).

\section{References}

1. Zhou P, Yang XL, Wang XG, Hu B, Zhang L, Zhang W, et al. A pneumonia outbreak associated with a new coronavirus of probable bat origin. Nature. 2020;579(7798):270-3.

2. Lu R, Zhao X, Li J, Niu P, Yang B, Wu H, et al. Genomic characterisation and epidemiology of 2019 novel coronavirus: implications for virus origins and receptor binding. Lancet. 2020;395(10224):565-74.

3. Yan Y, Chang L, Wang L. Laboratory testing of SARS-CoV, MERS-CoV, and SARS-CoV-2 (2019-nCoV): current status, challenges, and countermeasures. Rev Med Virol. 2020;30(3):e2106.

4. Yoshimoto FK. The proteins of severe acute respiratory syndrome coronavirus-2 (SARS CoV-2 or n-COV19), the cause of COVID19. Protein J. 2020;39(3):198-216.

5. Grunewald ME, Fehr AR, Athmer J, Perlman S. The coronavirus nucleocapsid protein is ADP-ribosylated. Virology. 2018;517:62-8.

6. Barlev-Gross M, Weiss S, Ben-Shmuel A, Sittner A, Eden K, Mazuz N, et al. Spike vs nucleocapsid SARS-CoV-2 antigen detection: application in nasopharyngeal swab specimens. Anal Bioanal Chem, 2021;1-10.

7. Yan Y, Shin WI, Pang YX, Meng Y, Lai J, You C, et al. The first 75 days of novel coronavirus (SARS-CoV-2) outbreak: recent advances, prevention, and treatment. Int J Environ Res Public Health. 2020;17(7).

8. Kucharski AJ, Klepac P, Conlan AJK, Kissler SM, Tang ML, Fry $\mathrm{H}$, et al. Effectiveness of isolation, testing, contact tracing, and physical distancing on reducing transmission of SARS-CoV-2 in different settings: a mathematical modelling study. Lancet Infect Dis. 2020;20(10):1151-60.

9. Pascarella G, Strumia A, Piliego C, Bruno F, Del Buono R, Costa F, et al. COVID-19 diagnosis and management: a comprehensive review. J Intern Med. 2020.

10. Israeli O, Beth-Din A, Paran N, Stein D, Lazar S, Weiss S, et al. Evaluating the efficacy of RT-qPCR SARS-CoV-2 direct approaches in comparison to RNA extraction. Int J Infec Dis. 2020;99:352-4.

11. Huang CG, Lee KM, Hsiao MJ, Yang SL, Huang PN, Gong YN, et al. Culture-based virus isolation to evaluate potential infectivity of clinical specimens tested for COVID-19. J Clin Microbiol. 2020;58(8).

12. Pekosz A, Parvu V, Li M, Andrews JC, Manabe YC, Kodsi S, et al. Antigen-based testing but not real-time polymerase chain reaction correlates with severe acute respiratory syndrome coronavirus 2 viral culture. Clin Infect Dis. 2021.

13. Li C, Ren L. Recent progress on the diagnosis of 2019 novel coronavirus. Transbound Emerg Dis. 2020;67(4):1485-91.

14. Wiseman J, D'Amico TA, Zawadzka S, Anyimadu H. False negative SARS-CoV-2 PCR - a case report and literature review. Respir Med Case Rep. 2020;31:101140. 
15. Woloshin S, Patel N, Kesselheim AS. False negative tests for SARS-CoV-2 infection - challenges and implications. N Engl J Med. 2020;383(6):e38.

16. Kanji JN, Zelyas N, MacDonald C, Pabbaraju K, Khan MN, Prasad A, et al. False negative rate of COVID-19 PCR testing: a discordant testing analysis. Virol J. 2021;18(1):13.

17. Gao J, Quan L. Current status of diagnostic testing for SARSCoV-2 infection and future developments: a review. Med Sci Monit. 2020;26:e928552.

18. Patel R. MALDI-TOF MS for the diagnosis of infectious diseases. Clin Chem. 2015;61(1):100-11.

19. Calderaro A, Arcangeletti MC, Rodighiero I, Buttrini M, Gorrini C, Motta F, et al. Matrix-assisted laser desorption/ionization time-of-flight (MALDI-TOF) mass spectrometry applied to virus identification. Sci Rep. 2014;4:6803.

20. Krokhin O, Li Y, Andonov A, Feldmann H, Flick R, Jones S, et al. Mass spectrometric characterization of proteins from the SARS virus: a preliminary report. Mol Cell Proteomics. 2003;2(5):346-56.

21. Sampath R, Hofstadler SA, Blyn LB, Eshoo MW, Hall TA, Massire $\mathrm{C}$, et al. Rapid identification of emerging pathogens: coronavirus. Emerg Infect Dis. 2005;11(3):373-9.

22. Kang X, Xu Y, Wu X, Liang Y, Wang C, Guo J, et al. Proteomic fingerprints for potential application to early diagnosis of severe acute respiratory syndrome. Clin Chem. 2005;51(1):56-64.

23. Ihling C, Tänzler D, Hagemann S, Kehlen A, Hüttelmaier S, Arlt $\mathrm{C}$, et al. Mass spectrometric identification of SARS-CoV-2 proteins from gargle solution samples of COVID-19 patients. J Proteome Res. 2020.

24 Cardozo KHM, Lebkuchen A, Okai GG, Schuch RA, Viana LG, Olive AN, et al. Establishing a mass spectrometry-based system for rapid detection of SARS-CoV-2 in large clinical sample cohorts. Nat Commun. 2020;11(1):6201.

25. Saadi J, Oueslati S, Bellanger L, Gallais F, Dortet L, RoqueAfonso AM, et al. Quantitative assessment of SARS-CoV-2 virus in nasopharyngeal swabs stored in transport medium by a straightforward LC-MS/MS assay targeting nucleocapsid, membrane, and spike proteins. J Proteome Res. 2021;20(2):1434-43.

26. Ahsan N, Rao RSP, Wilson RS, Punyamurtula U, Salvato F, Petersen M, et al. Mass spectrometry-based proteomic platforms for better understanding of SARS-CoV-2 induced pathogenesis and potential diagnostic approaches. Proteomics. 2021;e2000279.

27. Gouveia D, Grenga L, Gaillard JC, Gallais F, Bellanger L, Pible O, et al. Shortlisting SARS-CoV-2 peptides for targeted studies from experimental data-dependent acquisition tandem mass spectrometry data. Proteomics. 2020;20(14):e2000107.

28. Gouveia D, Miotello G, Gallais F, Gaillard J-C, Debroas S, Bellanger L, et al. Proteotyping SARS-CoV-2 virus from nasopharyngeal swabs: a proof-of-concept focused on a 3 min mass spectrometry window. J Proteome Res. 2020;19(11):4407-16.
29. Schuster O, Zvi A, Rosen O, Achdout H, Ben-Shmuel A, Shifman $\mathrm{O}$, et al. Specific and rapid SARS-CoV-2 identification based on LC-MS/MS analysis. ACS Omega. 2021;6(5):3525-34.

30. Grossegesse M, Hartkopf F, Nitsche A, Schaade L, Doellinger J, Muth T. Perspective on proteomics for virus detection in clinical samples. J Proteome Res. 2020;19(11):4380-8.

31. Zhang M, Li Y, Jing H, Wang N, Wu S, Wang Q, et al. Development of polyclonal-antibody-coated immunomagnetic beads for separation and detection of koi herpesvirus in large-volume samples. Arch Virol. 2020;165(4):973-6.

32. Zhu W, Yang X, Zhou Y, Yan Y. Immunomagnetic enrichment to evaluate the role of home environment specimens in transmission of enterovirus 71. Exp Ther Med. 2018;16(3):2355-62.

33. Jothikumar N, Cliver DO, Mariam TW. Immunomagnetic capture PCR for rapid concentration and detection of hepatitis A virus from environmental samples. Appl Environ Microbiol. 1998;64(2):504-8.

34. de Almeida FG, Vanzolini KL, Cass QB. Angiotensin converting enzyme immobilized on magnetic beads as a tool for ligand fishing. J Pharm Biomed Anal. 2017;132:159-64.

35. Renuse S, Vanderboom PM, Maus AD, Kemp JV, Gurtner KM, Madugundu AK, et al. A mass spectrometry-based targeted assay for detection of SARS-CoV-2 antigen from clinical specimens. EBioMedicine. 2021;69:103465-103465.

36. oy-Porat T, Makdasi E, Alcalay R, Mechaly A, Levy Y, Bercovich-Kinori A, et al. A panel of human neutralizing mAbs targeting SARS-CoV-2 spike at multiple epitopes. Nat Commun. 2020;11(1): 4303.

37. Makdasi E, Levy Y, Alcalay R, Noy-Porat T, Zahavy E, Mechaly A, et al. Neutralizing monoclonal anti-SARS-CoV-2 antibodies isolated from immunized rabbits define novel vulnerable spikeprotein epitope. Viruses. 2021;13(4).

38. Feldberg L, Schuster O, Elhanany E, Laskar O, Yitzhaki S, Gura $S$. Rapid and sensitive identification of ricin in environmental samples based on lactamyl agarose beads using LC-MS/MS (MRM). J Mass Spectrom. 2020;55(1):e4482.

39. Corman VM, Landt O, Kaiser M, Molenkamp R, Meijer A, Chu DK, et al. Detection of 2019 novel coronavirus (2019-nCoV) by real-time RT-PCR. Euro Surveill. 2020;25(3).

40. Commission E. 2002/657/EC: Commission Decision of 12 August 2002 implementing Council Directive 96/23/EC concerning the performance of analytical methods and the interpretation of results. 2002.

41. Smith KP, Cheng A, Chopelas A, DuBois-Coyne S, Mezghani I, Rodriguez S, et al. Large-scale, in-house production of viral transport media to support SARS-CoV-2 PCR testing in a multihospital health care network during the COVID-19 pandemic. J Clin Microbiol. 2020;58(8).

Publisher's Note Springer Nature remains neutral with regard to jurisdictional claims in published maps and institutional affiliations. 